\title{
Adaptation of the Scale of Coaching Performance (SCP) to the Greek Athletic System
}

1Dimitrios Papailiou

jpapailiou@yahoo.com

${ }^{2}$ George Kipreos

gkipreos17ex@yahoo.gr

${ }^{3}$ Antonios K. Travlos

atravlos@uop.gr

\section{Ethan Strigas}

astrigas@gmail.com

1,2,3Department of Sports, Organization and Management, University of Peloponnese, Sparta, Greece ${ }^{4}$ Department of Kinesiology, Recreation and Sport, Indiana State University, Indiana, USA

Doi:10.5901/mjss.2015.v6n6s1p232

\section{Abstract}

The scope of this study was to re-evaluate the Scale of Coaching Performance (SCP) in the Greek athletic system, re-assess its factor structure and items included and investigate club level participants. A questionnaire was constructed and distributed to a purposive sample of 340 club basketball coaches. Participants assessed the importance of the criteria included for the evaluation of basketball coaches. Three items initially included at the SCP were removed and seven new where added. Exploratory factor analysis supported the pre-determined four factor structure named: "Direct Task Behaviours", "Indirect Task Bahaviours", "Personal Products" and "Team Products". Confirmatory factor analysis revealed adequate fit between the model and the 25 items. Results supported the conceptual theory that a model should be adapted to the specific athletic environment and its dimensions and criteria should be re-examined at times.

Keywords: Basketball club coaches; coaching evaluation; model adaptation, evaluation criteria.

\section{Introduction}

Queries have been emerged on how accurate and reliable it is to implement similar coaching practices and methods to different countries, social environments and sports. McLean and Chelladurai (1995) have argued that philosophical orientations vary between clubs and universities. As a result, coach's decisions that reflect team's guidance are expected to vary as well. Many differences between team and individual sports have been also identified, such as team structure, group cohesion, outcomes, coaching behavioural styles, decision making strategies, coaching leadership styles, managerial and public relations coaching tasks (Barber \& Eckrich, 1998; Chen, 2003; Fizel \& D'itri, 1996). Papailiou, Strigas, Travlos and Kipreos (2015) highlighted the influence of the social environment on the coaching process, whereas Papailiou, Kipreos, Travlos and Strigas (2015) presented a list of environmental criteria that affect the coaching performance. At the same time, Lyle and Cushion (2010) expected coaching to be different not only among sports but also within sport, where multiple situations of training, competition and organization make coaching unique. Similarly, Pereira, Mesquita, and Graça, (2009) expected coaching behaviours to be different even between sessions of the same club, since practice levels and cognitive loads also change. Finally, Cushion, Harvey, Muir, and Nelson (2012) suggested coaching behaviours to be examined in both training and competition as well as at different periods in the season. 


\section{Literature Review}

Although personnel evaluation is an integral part of the coaching profession, performance evaluation is controversial and not without limitations (Kaprinis, Kipreos, Vrondou, \& Kakkos, 2013). A widely known coaching evaluation model is the Scale of Coaching Performance (SCP), constructed from McLean and Chelladurai (1995). It has been developed in Canada and used to several surveys since then (Chen, 2003; McLean \& Zakrajsek, 1996; Surujlal, Singh, \& MacLean, 2009; Zhang, Hou, Wang, \& Xiao, 2014). McLean and Chelladurai (1995) separated coaching process among dimensions that derive from coaching behavioural product factors and process factors. Data was collected from the Canadian Interuniversity Athletic Union. Results verified the construct of the model and revealed a consensus between administrators and coaches on the dimensions of coaching performance.

Likewise, Surujlal et al. (2009) also adopted the SCP and examined differences between South African (SA) and Canadian coaches and administrators. They concluded that there are statistically significant differences between the two countries, although the practical effect was small. Results strengthened suggestions that the SCP might be applicable only in Canada (Chen, 2003). Similarly, Mesquita, Isidro, and Rosado (2010) investigated coaches' preferences for sources of learning. They highlighted among others that Portuguese coaching education practices are by far different from the ones in other countries (UK, Australia, USA), with Canada included. Finally, Gilbert and Trudel (2004) gave an additional element of differentiation among countries. They indicated that although the majority of the surveys are made from coaches for coaches, there are additional types of participants (i.e. athletes, administrators, parents, officials,) that surround the coach and affect the coaching process. The philosophy, the expectations and the culture of these groups is not expected to be common across countries and sports; hence the coaching process varies accordingly.

\section{The Scope of the Study}

Several researchers advocated that a model should be reconfirmed with different populations (Chen, 2003), different athletic systems (Barber \& Eckrich, 1998) and its dimensions and items re-evaluated (MacLean, 1994). For these reasons, the aim of the current research was to satisfy those needs and therefore modify a coaching performance evaluation model to the Greek athletic system, re-assess its factor structure and items included and re-evaluate its validity, reliability, structure and consistency.

\section{Method}

The SCP (Mac Lean \& Chelladurai, 1995) was used to a sample of Greek club basketball coaches. It was chosen as the most representative and comprehensive scale of coaching process. It splited Product Factors into Team and Personal Products, whereas Process Factors was splited into Task Related and Maintenance Related behaviours. However, the Maintenance Related behaviours (Public Relations and Administrative Maintenance behaviours) considered not applicable at the Greek environment and for club coaches. For example, items like "Adhering to budget", "Being on time with paperwork", "Purchase of equipment" or "Establishing working relationships with parents" were considered not applicable. Similar coaching process models have also not adopted Public Relations and Administrative Maintenance behaviours (Côté, Salmela, Trudel, \& Baria, 1995; Franks, Johnson, \& Sinclair, 1988).

As a result, the remaining model was adapted in the Greek context. The items were translated in accordance with the Minimal Translation Criteria (Mapi Research Institute, 2002). Forward and backward translation methods were used. A panel of 10 experts was asked to examine the items in terms of clarity and completeness and identify confusing items. They also assessed the appropriateness of the items for the evaluation of a basketball coach. Three items initially included at the SCP were removed: ("Making the playoffs", "Recruiting a specific number of players" and "Receiving coaching awards"). After consultation with experienced coaches and an extensive review of the literature, seven new items where added. As a result, the modified SCP consisted of 27 items. Each item was answered on a 5-point multiple rating list, ranging from 1 (completely unimportant) to 5 (completely important). Instructions were as follows: "For the evaluation of a basketball coach, I would rate the following item as:"

\subsection{Participants}

A purposive sample of 340 club basketball coaches was evaluated. Questionnaires were personally distributed and 323 usable responses were collected. Participants presented at least two years of coaching experience at competitive leagues. Their average age was $37.41(\min =23, \max =60, S D=7.37)$ and their average coaching experience was 10.49 
years ( $\min =2, \max =40, S D=6.88)$. The number of coaches having experience at professional leagues was $78(24.2 \%)$, at national leagues 49 (15.5\%) and at local leagues 196 (60.7\%).

\section{Data Analysis}

The factor structure and validity of the modified SCP were evaluated through exploratory factor analysis (EFA). Principal component analysis with no rotation was conducted to determine the extracted factors. The adequacy of the sample and the homogeneity of variances were examined with the Kaiser-Meyer-Olkin test (KMO) and the Bartlett's test of sphericity. In addition, factorability of $\mathrm{R}$ was also tested through the anti-image correlation matrix. The criteria followed for the factor extraction were: (a) eigenvalue greater than one; (b) the cumulative extraction sums of squared loadings; (c) the scree plot, and (d) the number of factors that could be best interpreted by theory (Tabachnick \& Fidell, 2013). Moreover, in order to accept the questionnaire's factor structure, the following criteria were considered: (a) item loadings of .40 and above, and (b) at least 10 difference in the loadings when items were cross-loaded (Howell, 2002; Tabachnick \& Fidell, 2013). When the appropriate number of factors was extracted, oblique rotation was implemented. Cronbach's alpha, inter-item correlations and item to total correlations were calculated to examine the internal consistency of the scale. IBM SPSS 22 was used to analyze this part of the survey.

Confirmatory factor (CFA) analysis was also conducted to examine the validity of the scale. Its construct was tested against the absolute fit SRMR, which is suggested as the most generally preferred (Brown, 2015), the parcimony correction RMSEA and its $90 \%$ confidence interval, the Comparative Fit Index (CFI), the Goodness of Fit Index (GFI), and the ratio X2/df (Harrington, 2009; Tabachnick \& Fidell, 2013). The acceptable limits recommended by Bentler (1990), Bollen (1989), Brown (2015), Kline (2011) and Tabachnick and Fidell (2013) were: $\chi^{2} / d f$ ratio $<3, C F I \geq .90, G F I \geq .90$, RMSEA $\leq .06$ and SRMS $\leq .08$.

\section{Results}

\subsection{Exploratory Factor Analysis}

The KMO measure was .94, higher enough from .90 indicating sampling adequacy to perform factor analysis. Bartlett's test of sphericity was significant (4962.22 $d f=351, p<001)$, indicating that data do not produce an identity matrix and are acceptable for factor analysis, The off-diagonal prices of the anti-image correlations matrix ranged from .74 to .97, indicating also sampling adequacy. In addition, the criteria adopted for factor extraction resulted, in accordance with the SCP model, to a 4 factor solution, which explained the $60.83 \%$ of the overall variance. The off-diagonal correlations of the Component Correlation Matrix presented most values below .30, indicating the orthogonal rotation more appropriate (Tabachnick \& Fidell, 2013). Nevertheless, the factors were expected to intercorrelate, since they were parts of the broader concept of coaching performance. In addition, oblique solutions are more connected with CFA that followed, than orthogonal ones (Brown, 2015). In such cases, Brown (2015) suggested the oblique rotation as more realistic and accurate.

Table 1. Item loadings, communalities (Com), means (M) and standard deviation (SD) for the 27 items of the modified $\operatorname{SCP}(N=323)$.

\begin{tabular}{|c|c|c|c|c|c|}
\hline \multicolumn{6}{|l|}{ Structure Matrix } \\
\hline & \multicolumn{4}{|c|}{ Component } & \multirow[b]{2}{*}{ Com M SD } \\
\hline & 1 & 2 & 3 & 4 & \\
\hline 1. Improving athletes' performance from previous year & .846 & & & & .7234 .47 .768 \\
\hline 2. Communicating with athletes & .845 & & & & .7284 .65 .704 \\
\hline 3. Making coaching decisions during competition & .835 & & & & .7294 .76 .621 \\
\hline 4. Teaching techniques during practice & .822 & & & & .6814 .62 .740 \\
\hline 5. Motivating athletes toward higher levels of achievements & .803 & & & & .6844 .44 .804 \\
\hline $\begin{array}{l}\text { 6. Applying sport knowledge (theoretical knowledge, experience, ability to analyze, } \\
\text { compose, adapt and apply). }\end{array}$ & .785 & & & & .6244 .61 .689 \\
\hline 7. Planning and preparing for the preseason. season and postseason & .771 & & & & .6184 .48 .797 \\
\hline 8. Maintaining players' health & .758 & & & & .6014 .52 .798 \\
\hline 9. Achieve team's peak performance according to plan & .755 & & & & .5984 .36 .800 \\
\hline 10. Establishment/Application of game philosophy & .740 & & & & .5624 .38 .796 \\
\hline
\end{tabular}




\begin{tabular}{|c|c|c|c|}
\hline 11. Applying conditioning principles & .725 & -.404 & .5894 .19 .844 \\
\hline 12. Improving of the team's game performance compared to previous season & .719 & & .5784 .25 .804 \\
\hline 13. Utilizing game tactics and strategies & .712 & & .5654 .35 .736 \\
\hline 14. Establishing a good athlete/coach relationship & .693 & & .4944 .45 .784 \\
\hline 15. Ability to identify talent & .681 .410 & & .4974 .17 .823 \\
\hline 16. Conducting practice sessions & .584 & & .3544 .32 .857 \\
\hline 17. Making reqruiting contacts & .827 & & .7243 .20 .929 \\
\hline 18. Establishing a recruiting plan & .808 & & .6923 .60 .889 \\
\hline 19. Reqruiting quality athletes & .749 & & .5823 .71 .906 \\
\hline 20. Scouting opponents & .676 & & .4863 .67 .902 \\
\hline 21. Publication (periodicals. newspapers. websites. books) & & -.836 & .7232 .761 .077 \\
\hline 22. Speaking/Lecturing/Presentations on coaching issues & & -.829 & .7203 .321 .066 \\
\hline 23. Attending seminars & .585 & -.638 & .6094 .15 .939 \\
\hline 24. Winning a championship & \multicolumn{3}{|c|}{.757 .5913 .211 .018} \\
\hline 25. Team win/loss record & \multicolumn{3}{|c|}{.748 .5982 .99 .913} \\
\hline 26. Improving of the team's ranking compared to previous season & .445 & \multicolumn{2}{|c|}{.685 .5603 .63 .915} \\
\hline 27. Developing statistical data & .517 & \multicolumn{2}{|c|}{$-.435 .531 .5143 .68 .875$} \\
\hline
\end{tabular}

Extraction Method: Principal Component Analysis.

Rotation Method: Oblimin with Kaiser Normalization.

A fixed number of four factors to extract were used with principal components analysis and oblique rotation for the 27 items. Item loadings and communalities ranged from .531 to .846 and .354 to .729 respectively (table 1). One item "Attending seminars" revealed less than .10 difference between two factors loadings, whereas another item "Developing statistical data" revealed loadings above .40 in three factors and cross loadings below .10 in two factors. Communalities reveal the percent of variance that a factor overlaps the variable. Although most communalities were "in the range of .5" or above (Tabachnick \& Fidell, 2013), one item ("Conducting practice sessions") presented communality below 4. Nevertheless, several authors (Brown, 2015; Tabachnick \& Fidell, 2013) stated that the decision for a criterion exclusion from a scale should not be made on results of factor analysis alone, but in conjunction with what is known about the construct that the item or the scale assesses. As a consequence, only the item that loaded to three factors was deleted and the others were kept for further inspection. Means of each item were ranged from 2.76 to 4.76 (SD=.621-1.077) (table 1). The four factors were named "Direct Task Behaviours" (DTB), "Indirect Task Behaviours" (ITB), "Personal Products" (PP) and "Team Products" (TP), in accordance with the SCP. Finally, the internal consistency of each factor and the scale as a unity was examined. The Cronbach's a ranged higher than the cut-off point of .70 (Nunnaly \& Bernstein, 1994), except of the TP factor ( .95 for DTB, .78 for ITB, .77 for PP, .64 for TP and .93 for the whole scale). However, alpha values depend on the number of items (Brown, 2015). In cases where factor items are less than ten, Cronbach's a values above .60 are equally adequate (George \& Mallery, 2003; Pallant, 2005)

\subsection{Confirmatory Factor Analysis}

The symmetry and the peakedness of the distribution was examined by skewness and kyrtosis, respectively (Tabachnick and Fidell, 2013). All absolute values were below the limits proposed by Kline (2011). Multivariate outliers ( $\mathrm{N}=15)$, using Mahalanobis distance, were detected and removed. As a consequence, the sample was reduced to 308.

In order to examine the structure of the 4-factor scale, the maximum likelihood method, with IBM AMOS 20, was employed. Several goodness-of-fit indices revealed a weak fit between data and the four factor solution $\left(X^{2}=773.32\right.$, $d f=293, p<.001, X^{2} \mathrm{ldf}=2.64, \mathrm{RMSEA}=.07$ (90\% Cl of RMSEA=0.67-0.79), GFI=.84, CFI=.88, SRMR=.08). Examination of modification indices (MI) revealed: (a) the item: "Attending coaching seminars" was loaded in two factors, which was also identified at the EFA and (b) covariances between the errors for "Improving of the team's ranking compared to previous season" and "Improving of the team's game performance compared to previous season" and between the errors for "Communicating with athletes" and "Establishing a good athlete/coach relationship" were high (44.89 and 44.44, respectively). It makes sense that improvement of team's performance most of the times strongly relates with improvement of team's ranking. Similarly, it is rational to expect a good communication between the coach and the athletes to result to a good relationship between them. As a result, Mls were accepted and CFA was re-executed. The nested model (Figure 1), the one produced from the parent model, revealed $X^{2}=610.20, d f=267, p<.001$. The $X^{2}$ and $d f$ difference for the two models $\left(X^{2}=163.12\right.$ and $\left.d f=26 p<.001\right)$ was significant, which indicates that modifications improved the model (Brown, 2015; Harrington, 2009). 
All goodness-of-fit indices revealed an acceptable fit between data and the four factor solution: $X^{2}=610.20, d f=267$, $p<.001, X^{2} l d f=2.29, \mathrm{RMSEA}=.06(90 \% \mathrm{Cl}$ of RMSEA=.058-.071), GFI=.87, CFI=.91, SRMR=.06. Additional changes did not prove significant nor were meaningful. As a result, no further changes were made (Harrington, 2009). Standardized regression weights for all items ranged from .50 to .90 and factor correlations ranged from .39 to .65 (Figure 1). They were neither too high, so as to assume that they measure the same construct, nor too low so as to assume that they are completely irrelevant (Harrington, 2009). Means (M) and Standard Deviations (SD) for the four factors are presented in table 2.

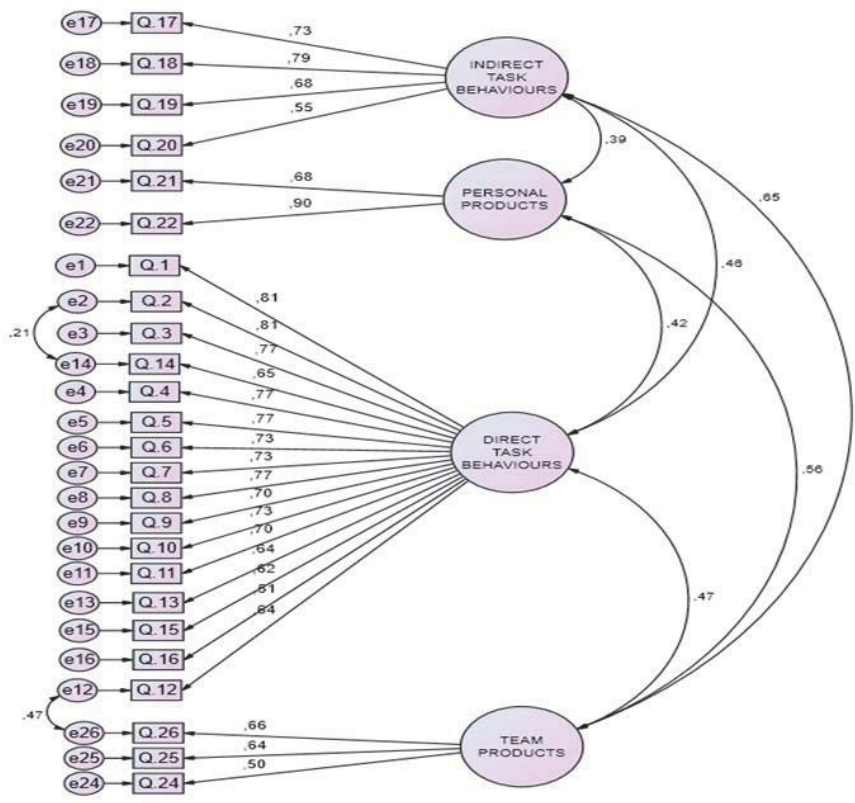

Figure 1. Four-factor model produced from CFA for the 25 items of the modified SCP $(N=308)$.

Table 5.1. Means (M) and Standard deviations (SD) of the four factors for the 25 items ( $N=308)$.

\begin{tabular}{lllcc}
\hline \hline Factors & & M & SD \\
& 1. & Direct Task Behaviours & 4.44 & .56 \\
& 2. & Indirect Task Bahaviours & 3.54 & .71 \\
& 3. & Team Products & 3.28 & .73 \\
4. & Personal Products & 3.04 & .96 \\
\hline \hline
\end{tabular}

\section{Discussion}

Results indicated an acceptable fit between the data and the proposed four factor solution. The first factor "Direct Task Behaviours" was consisted of sixteen (16) items that referred to the direct responsibilities of the coach (e.g. planning, decision making, applying coaching, physical condition and behavioural practices). The second factor "Indirect Task Behaviours" was consisted of four (4) items that referred to recruiting and scouting responsibilities of the coach. The third factor "Personal Products" was consisted of two (2) items that referred to speaking and publishing activities of the coach. Finally, the fourth factor "Team Products" consisted of three (3) items that referred to team results and achievements (e.g. winning a championship, win/loss record). A similar adaptation of the SCP to the South African context produced twelve (12), five (5), six (6) and five (5) items per factor, respectively (Surujlal et al., 2009).

Moreover, both EFA and CFA validated the model's construct. Previous applications of the SCP at different athletic 
domains proved controversial. The SCP was found valid and reliable for the Canadian intercollegiate population (MacLean \& Chelladurai, 1995). Similarly, the modified SCP was also proved valid and reliable for the South African's athletic context. On the contrary, Chen (2003) found unsatisfactory factorial reliability and validity using NCAA sample, indicating no fit between the scale and the United States athletic system. At the Greek environment in particular, the SCP revealed an acceptable fit between the data and the four factor solution and satisfactory factor loadings.

The internal consistency of the factors and the scale as a unity were also acceptable. In all studies where the SCP was used, the "Team Products" factor revealed marginal internal consistency. However, any kind of team results consists of an integral part of coaching performance evaluation. It is very innovating and pioneering to assess a coach without considering team's outcomes. Future research should focus on this issue, increase the number of items included and improve its internal consistency.

The scope of this survey was not to investigate differences among populations (e.g. coaches and administrators). However, it is suggested for future studies to examine not only the application of the SCP to different countries, but also to multiple populations (e.g. players, administrators, parents, spectators). Administrators' opinions, who decide whether coaches will be hired or fired, should receive additional research interest (Fizel \& D'itri, 1996; Surujlal, et al., 2009). In addition, it would be interesting to modify and apply the SCP to several team or individual sports. Finally, the environment is extremely important for coaching performance evaluation. Future research might focus on environmental and situational factors and how they mediate or moderate the SCP construct.

\section{References}

Barber, H., \& Eckrich, J. (1998). Methods and criteria employed in the evaluation of intercollegiate coaches. Journal of Sport Management, 12, 301-322.

Bentler, P. M. (1990). Comparative fit indices in structural equation models. Psychological Bulletin, 107(2), 238-246.

Bollen, K. A. (1989). Structural Equation with Latent Variables. New York: Wiley.

Brown, T. A. (2015). Confirmatory factor analysis for applied research. (2nd ed.), New York, NY: Guilford Press

Chen, L. (2003). Examination of scale of coaching performance with the NCAA sample. Measurement in Physical Education and Exercise Science, 7(3), 175-197.

Côté, J., Salmela, J., Trudel, P., \& Baria, A. (1995). The coaching model: A grounded assessment of expert gymnastic coaches' knowledge. Journal of Sport \& Exercise Psychology, 17(1), 1-17.

Cushion, C., Harvey, S., Muir, B., \& Nelson, L. (2012). Developing the Coach Analysis and Intervention System (CAIS): Establishing validity and reliability of a computerised systematic observation instrument. Journal of Sports Sciences, 30(2), 201-216.

Fizel, J., \& D'itri, M. (1996). Estimating managerial efficiency: The case of college basketball coaches. Journal of Sport Management, 10, 435-445.

Franks, I. M., Johnson, R. B., \& Sinclair, G. D. (1988). The development of a computerized coaching analysis system for recording behavior in sporting environments. Journal of Teaching in Physical Education, 8(1), 23-32.

George, D., \& Mallery, P. (2003). SPSS for Windows step by step: A simple guide and reference. 11.0 update (4th ed.). Boston: Allyn \& Bacon.

Gilbert, W. D., \& Trudel, P. (2004). Analysis of coaching science research published from 1970-2001. Research Quarterly for Exercise and Sport, 75(4), 388-399.

Harrington, D. (2009). Confirmatory Factor Analysis, Oxford University Press, New York.

Howell, D. (2002). Statistical methods for psychology, (5 $5^{\text {th }}$ ed.), Pacific Grove, Duxbury.

Kaprinis, S., Kipreos, G., Vrondou, O., \& Kakkos, V. (2013). Employee performance appraisal in health clubs and sport organizations: a review. American Journal of Sports Science, 1(4), 44-57.

Kline, R. B. (2010). Principles and practice of structural equation modelling (3nd ed.), New York: Guilford Press.

Lyle J. and Cushion C.J. (2010) 'Narrowing the field: Some key questions about sports coaching', in Lyle, J. and Cushion, C. (Eds), Sports Coaching Professionalization and practice, Elsevier, London, pp 243-253.

MacLean, J. (1994). Personnel evaluation in education: A model for job-specific Criteria. The Clearing House, 68(1), 47-51.

MacLean, J. C., \& Chelladurai, P. (1995). Dimensions of coaching performance: Development of a scale. Journal of Sport Management, 9(2), $194-207$.

MacLean, J., \& Zakrajsek, D. (1996). Factors considered important for evaluating Canadian university athletic coaches. Journal of Sport Management, 10, 446-462.

MAPI Institute (2012). Linguistic Validation Manual for Health Outcome Assessments, $2^{\text {nd }}$ ed., MAPI Research Trust, Lyon.

Mesquita, I., Isidro, S., \& Rosado, A. (2010). Portuguese coaches' perceptions of and preferences for knowledge sources related to their professional background. Journal of Sports Science \& Medicine, 9(3), 480-489.

Nunnally, J. C., \& Bernstein, I. H. (1994). The theory of measurement error. Psychometric theory, 209-247.

Pallant, J. (2005). SPSS Survival Manual: A Step by Step Guide to Data Analysis Using SPSS for Windows. Australia: Australian Copyright.

Papailiou D., Kipreos G., Travlos A. K., \& Strigas E. (2015). Coaching evaluation, coaching environment and environmental criteria that 
influence coaching performance: An Overview. Scholars Journal of Arts, Humanities and Social Sciences, 3(6), 1174-1177.

Papailiou, D, Strigas, E, Travlos, A. K., \& Kipreos, G. (2015). The influence of the social context and the coaching environment on the coaching process and performance evaluation. Scholars Journal of Arts, Humanities and Social Sciences, 3(6A), 1115-1119.

Pereira, F., Mesquita, I., \& Graça, A. (2009). Accountability systems and instructional approaches in youth volleyball training. Journal of Sports Science \& medicine, 8(3), 366-373.

Surujlal, J., Singh, P. C. \& MacLean, J. (2009). Performance appraisal of coaches: A comparative study. African Journal for Physical, Health Education, Recreation and Dance, 15(1), 74-90.

Tabachnick, B., \& Fidell, L. (2013). Using Multivariate Statistics, (6 $6^{\text {th }}$ ed.), Pearson Education, New York.

Zhang, Q., Hou, B., Wang Y., \& Xiao, Y. (2014). A comprehensive model for evaluation of sport coaches' performance. International Journal of Engineering and Innovative Technology, 3(9), 265-271. 